\title{
The effect of Shape of "Curtain wall" on their strength Case Study: Bojnord University Buildings
}

\author{
Mehran Mohammadi1* \\ University of Bojnord, Faculty of Engineering, Iran \\ email:m.mohamadi@ub.ac.ir
}

\begin{abstract}
The curtain walls are used in buildings due to their aesthetic, thermal and lighting aspects. The structural performance of curtain wall systems to meet the structural requirements of the standards must be carefully analyzed and designed because the facades are in most cases severely affected by environmental impacts. It is necessary to analyze and design this facade as an integral part of the building as an integrated outer shell against wind power. In this study, the glass walls of the buildings of the Central Organization and the Faculty of Art of Bojnord University with aluminum frame in curved and flat geometric forms suggested by architectural designer, analyzed and designed. In addition to examining the stresses and their displacements against the applied forces, the status of the glass facade shielding structure has been investigated in different modes with aluminum and steel composite frames and the most appropriate geometric form of this facade has been selected based on structural analysis. Free-form architecture is one of the major challenges for architects, engineers, and the building industry and The study show that the Curtain Wall curved designs are more robust.
\end{abstract}

Keywords: Curtain wall, Facade Architecture Design, Facade structure, Wind pressure

\section{Introduction}

It has always been tried to create more efficient separations between the interior and exterior environments. What started as the utilization of natural shelters has evolved into elaborate assemblies of highly complex manufactured components (Richman, \& Pressnail, 2009). The curtain-wall system is a typical secondary structure in buildings, and combines aluminum and glass. This system provides all the required functions of an external wall that usually does not contribute to the load-bearing characteristics of the building structure. From the 1960s, it was realized that a curtain-wall system could enhance a building's interior natural lighting and concurrently contribute to achieving an improved aesthetic exterior design. This means that the principal structural mission of a curtain wall is to isolate the interior of a building from the external environment and, in particular, from the impact of environmental actions (Baniotopoulos, Nikolaidis, \& Moutsanidis, 2016). The invention of the curtain wall - also called the elemental façade significantly influenced the image of many contemporary cities (Brzezicki, 2018). Glazing facades are widely used in building structures, due to a series of aesthetic, thermal, lightening aspects. In most of the cases, wide transparent surfaces are created in commercial, residential as well as strategic buildings, including airports, museums, offices, etc (Bedon, \& Amadio, 2018). In addition to impacting energy use, building fenestrations also have undeniable impacts on daylight admission and consequently indoor environmental conditions. Among all contributions that building envelopes can have on IEQ (Indoor Environmental Quality), the control of incoming daylight is particularly important given the extensive effects that day lighting can have on occupants' health and well-being (Yi, Sharston, \& Barakat, 2019). Glass curtain-wall systems are extensively used in modern construction. They can be manufactured as building facades with high-efficiency properties prescribed by the designer; among these properties, the most important are high strength-to-self-weight ratio, serviceability requirements, recyclability of the constituent parts, as well as transparency and overall aesthetic characteristics. The structural performance of curtain-wall systems has to be meticulously analyzed and designed to fulfill structural Euro codes requirements because facades are, in most cases, subjected to strong environmental actions. In addition, as a second design step, by applying advanced finite-element analysis schemes and taking into account structural design criteria, an optimal structural design of the glass curtain-wall system has to be carried out to achieve cost minimization once structural integrity and serviceability requirements have been fulfilled (Baniotopoulos, Nikolaidis, \& Moutsanidis, 2016). The use of electric lights inside an office environment strongly affects the total energy demand both directly, with electricity consumption, and indirectly, by introducing more or less loads in the environment and thus causing different demands for space heating and cooling. Therefore, it is very important to model the day lighting strategy that best represents the real use of electric lights in offices (Rapone, \& Saro, 2012). 
Therefore, the advantages of the Curtin Wall system are: the ability to use natural light, the ability to use double glazing, the ability to create temperature insulation surfaces using thermal brake profiles, the ability to run in full aluminum, no color limitation, the strength and solidity and unity, moisture and wind and rain insulation, low maintenance cost, sound insulation, fireproofing and fire safety, lightweight and reduced dead load compared to structural wall, reduced running time, less floor space occupancy, greater plasticity and flexibility especially against tremors and earthquakes.

In most buildings, facades cover about 20 to 30 percent of the total cost of construction and require special attention to the design, engineering and performing process. In a general subdivision, the types of modern facades can be divided into transparent (light passing) and opaque materials (such as composite aluminum sheets) or a combination of these two. With the development of glass production machinery, the use of this material has been gradually increased in the facades of modern buildings and glass is being used as the most common transparent forming component in new buildings. Glass and wall have certain functions in the construction which their composition in glass walls necessitates the compound function. In these buildings, the wall structure should have sufficient strength to load-bearing between the supporting points or attachment points to the structural frame and should be sufficiently resistant to the lateral pressures of the wind. The primary task of the glass wall, on the other hand, is to provide sufficient light input and optimum energy consumption for efficient daily activities. Transparent and translucent facades have different types, and three of them are common as Cable Truss, Curtin Wall and Spider (Fig. 1). The Curtin Wall system is discussed in this paper. In fact Curtain Wall are glass walls enclosed in a sheath of aluminum sheets and in some cases may be supported by a structure. This type of facade is completely industrial manufactured and the installation conditions are such that it has some flexibility in the face of earthquakes or other potential building forces in emergencies. This type of facade is manufactured and implemented in a form of frameless and facecap.

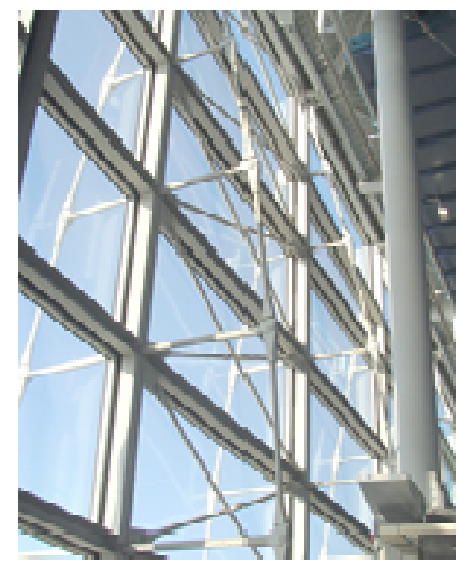

A

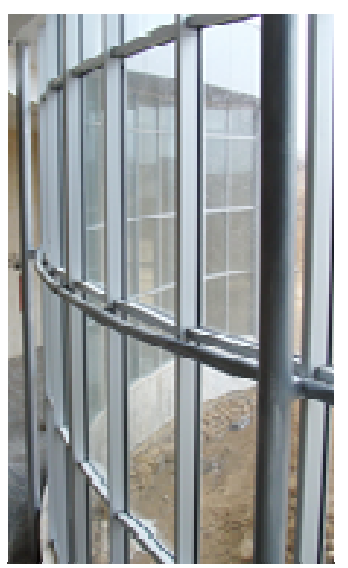

$B$

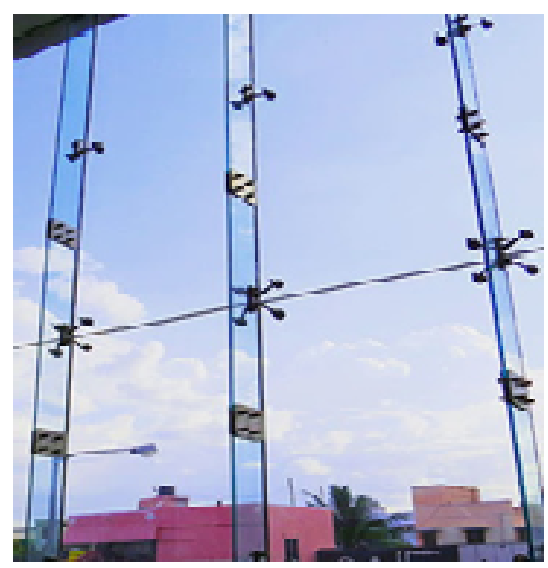

C

FIG.1 Transparent facades: A)Cable truss. B) Curtain wall. C) Spider

In this study, the glass walls of the buildings of the Central Organization and the Faculty of Arts of Bojnourd University were examined with an executive view. The architecteral designer has suggested glass facade in curved and flat geometrical forms, and choosing the most suitable option is based on the analysis of the metal frame structure and by examining its stresses and displacements against the applied forces. The status of the glass facade structure is controlled in various modes and the most appropriate geometric form of this facade is selected based on structural analysis and accordingly it has been implemented. Therefore, this study is conducted with a practical look and the impact of the structure on geometric forms of architecture.

\section{Introducing the geometric form of facad of buildings}

Overall, more experimental assessments are needed in order to get indispensable information regarding design characteristics, dynamic operation, and physical properties, as, so far, only a few responsive materials available in the building industry make their technical information available. Furthermore, assessments should be done at building scale, as these materials might behave unexpectedly and the value of their reaction might be non-linear at different scales (Juaristi, Barrio, Knaack, \& Acebo, 2018). Building facade has a significant impact on the environmental and economic performance of buildings and projects. The specification of their elements at the early design phase depends on numerous technical, environmental and economic factors and involves several stakeholders. The procurement and delivery of the facade work package from the early design phase, through detailed design and manufacture, to installation is a process with several inherent risk factors due to the involved cost, technical and engineering complexities and its position on the critical path in all projects. The complexity of specifying at the early design phases is exacerbated by factors such as the inadequate technical knowledge of stakeholders involved in the decision making process, the non-involvement of building facade consultants, the 
late involvement of specialist facade subcontractors (Kassem, \& Mitchell, 2015). Therefore, prior to implementation steps, it is necessary to analyze the structures of Curtin Wall and considering the interests of all stakeholders, including the employer, consultant, operator, contractors and even partial contractors. It is essential to identify the dimensions of the work, taking into account all the applicable standards, as well as the limitations, and then put the 3-D facade analysis on the agenda.

\subsection{Central Organization Building of Bojnourd University}

The central organization building of the University of Bojnourd is 5,000 square meters of infrastructure consists of 3 blocks of which the main (middle) block of 3,000 square meters and two symmetrical blocks of 1000 square meters are located on either side. Its middle block is designed with 4 floors and its two side blocks on two floors. The entrance is to the north and has glass facades on the last two floors on the north and south sides. The building height is 18 meters. Two alternatives have been proposed with flat and curved form in designing the building for Curtain Wall in the last two floors. In this paper, both proposals have been investigated considering the differences of architecture, modeling and analysis and then it is concluded.

In the flat model, in architectural view, the structure and glass wall area is lower, but in the curved model the structural area of the last 2 floors is increased and some of the wall area is added as well, which the difference of these two forms should be analyzed in term of the changes in structure size and costs of Curtin Wall. It should be noted that the length of the glass wall is $33.71 \mathrm{~m}$ in the flat form and $34.85 \mathrm{~m}$ in the curved form and its height of the two floors is $8 \mathrm{~m}$. The curved wall is therefore 1.14 meters longer and 8.83 square meters larger. The horizontal elements of the Curtain Wall are the sub elements and the vertical elements are the main elements. The cross frames are aluminum and there is a double glaze between them with a thickness of $6 \mathrm{~mm}$ and a distance of $1 \mathrm{~cm}$. (Figure 2)

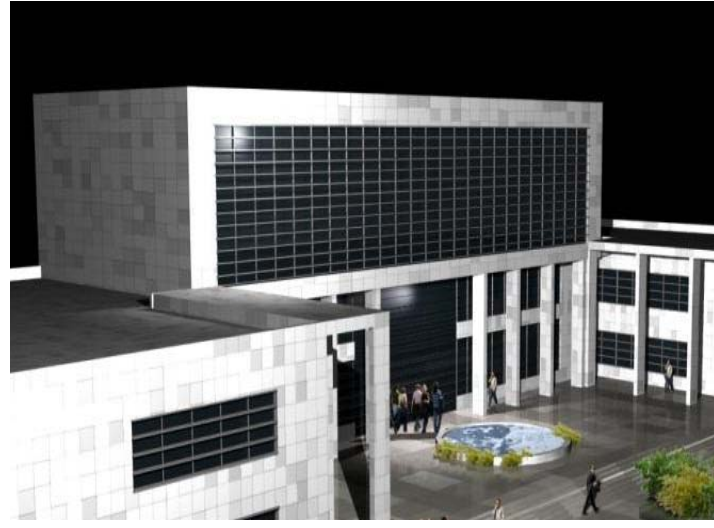

A

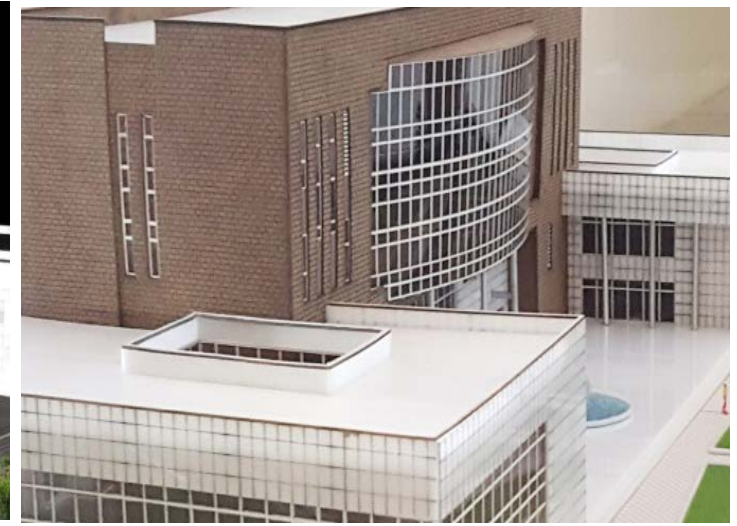

$B$

FIG. 2 Central Organization Building Curtain wall In two alternatives: A) Flat B) Curve

\subsection{Faculty of Art Building of Bojnourd University}

The Faculty of Art building includes 8 interconnected building blocks with 8,000 square meters of infrastructure. The U-shaped complex, open to the northeast, has a central courtyard and the boundary of the building is connected to this inner courtyard by a glass facade. The building facade is Curtain Wall, along its corridor toward the central courtyard. The building has a maximum height of 15 meters designed at one to three floors at various points depending on land use and slope,. Its western side includes the library, the computer site, the office part and the classrooms, and its eastern side contains the amphitheater and the atelier class in two blocks $\mathrm{F}$ and $\mathrm{G}$. The glass wall is combined with a composite aluminum façade in some points (Figure 3). 


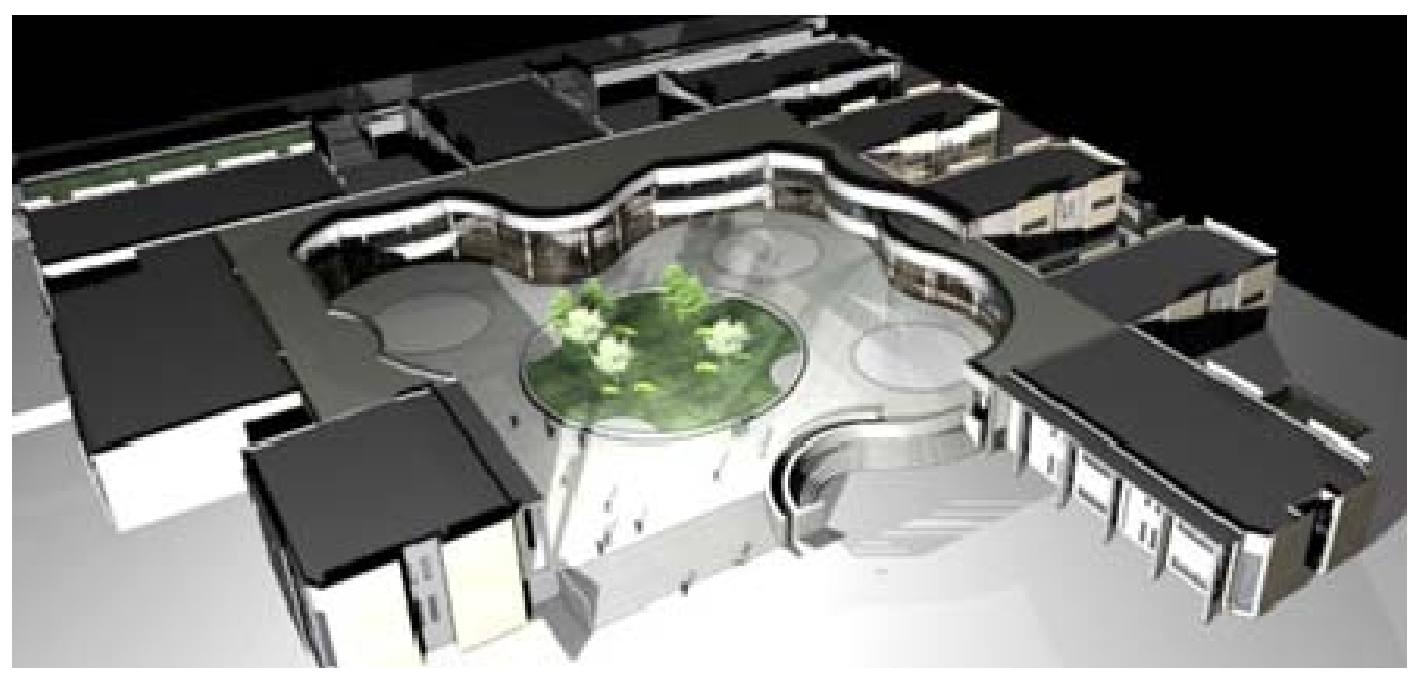

FIG. 3 Faculty of Art building with curved shapes in the inner courtyard

The structural system of the building is of the flexural frame of reinforced concrete with concrete slab roofs and a glass facade is between the building and the yard. The northern part of the glass facade begins at a height of about six meters and then passes through the seams where the balconies and openings continue to collide with the floor. In fact, the building in this section has three heights (ground level, first floor and roof) that collide with each other to create a path to the building. The horizontal elements of the Curtain Wall are the subelements and the main elements are the vertical elements. The cross frames are aluminum and there is a double glaze between them with a thickness of $6 \mathrm{~mm}$ and a distance of $1 \mathrm{~cm}$. cross section of facade is not the same in different parts of the building (Fig. 4)

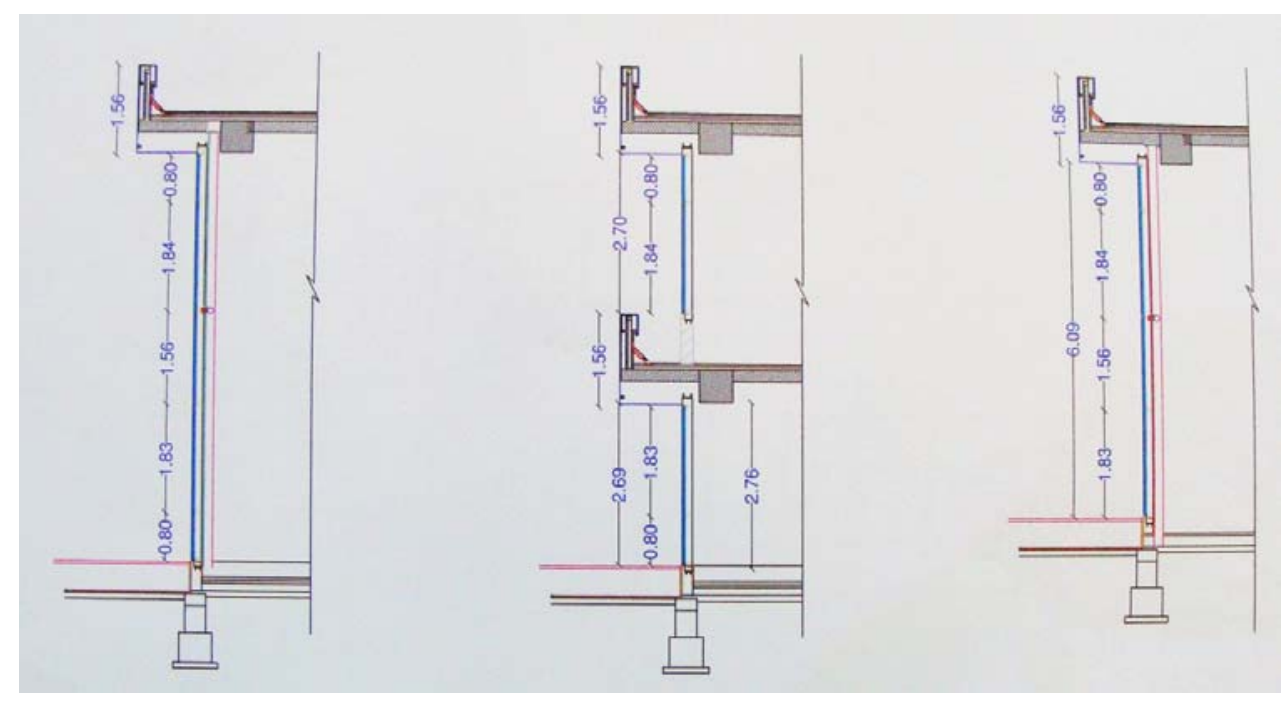

FIG. 4 Cross section of façade, Faculty of Art building

\section{Exploring Structural Analysis}

When designing structural glass systems three principal considerations have to be taken into account: performance, appearance and economy. In curtain-wall systems, these requirements are closely connected to the form and the position of the supporting metal structure and anchoring system to the building frame. The curtainwall system is usually designed in a modular way, consisting of a series of prefabricated aluminum profile components and connection brackets that support the glass panels (Baniotopoulos, Nikolaidis, \& Moutsanidis, 2016). It is a crucial issue for the facade manufacturer, owner or contractor, and designer to evaluate the longterm performance of a facade system (Ilter, Tavil, \& Celik, 2015).

The forces on the aluminum-glass structure commonly considered in its calculations include: element weight (Dead Load), wind, earthquake and heat loads. The aluminum frame resistance should be checked after loading. The DL of the structure consists of the weight of aluminum and glass which is considered in the analytical software model considering the specific mass of the material. In the case of earthquake lateral load, the wall is considered as an attachment to the structure and its earthquake lateral force was calculated according to the 
regulations with regard to glass and aluminum frames and was not determining the wind force and the wind force, considering the lightness of the wall, is several times more than earthquake force.

Given that the glass in this model is considered as Shell elements, the wind load is calculated and considered on 3D surface model. Due to the complexity of the form of the discussed glass facades, and for greater accuracy, the modeling has been carefully performed with all materials and analyzed with finite element software. The value of elasticity modulus and its yield stress in structural analysis is used to define aluminum properties according to the type of aluminum.

\subsection{Structural Analysis of Central Organization Building}

Glass differs from other building materials in aspect of being an extremely brittle material and breaking without a forewarning. This material property of brittleness has to be taken into account when designing large glass facades (Taywade, \& Shejwal, 2015). Therefore, the glass was also considered with the specific mechanical properties in the modeling.

The curtain wall of Bojnord University Central Organization Building (COB) is modeled on aluminum frames and Shell elements on the glass and is aligned to the floor panels. In both flat and curved models the aluminum elements were modeled on the basis of common profiles in the market. And glass was also defined as new material with specific weight and equivalent dimensions in the model. In this modeling, while controlling the permissible stresses of the frame, its displacements were also controlled. Figure 5 illustrates the results of the analysis and displacement of two different flat and curved structures.

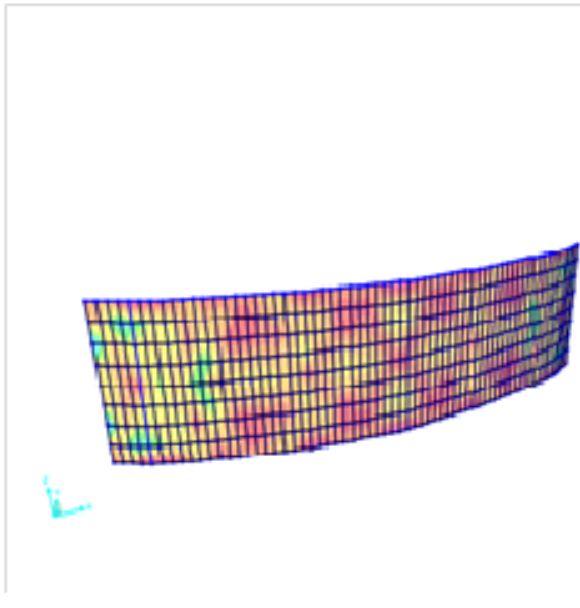

A

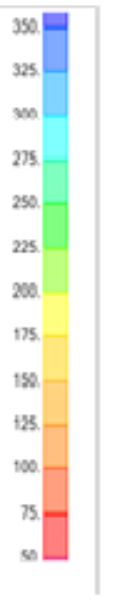

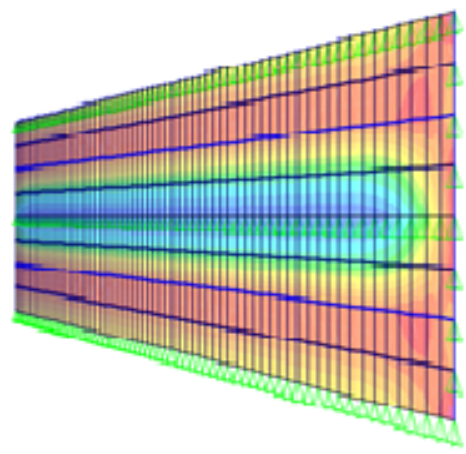

$B$

FIG. 5 Central office building Curtain wall analysis in two cases A) Curved. B) Flat

\subsection{Structural Analysis of Faculty of Art Building}

The curtain wall of Bojnourd's Faculty of Art building is modeled on aluminum frames and Shell elements on theglass and is aligned to the floor panels. In both flat and curved models the aluminum elements were modeled on the basis of common profiles in the market. And glass was also defined as new material with specific weight and equivalent dimensions in the model. In this modeling, while controlling the permissible stresses of the frame, its displacements were also controlled. Figure 6 illustrates the results of the analysis and displacement of two different flat and curved structures.

The use of steel in load-bearing structures improves the transparency of facades because it has been possible to keep the load-bearing structure slender. By using steel as a load bearing structure, it is possible to keep the transparency restricting structures slim (Taywade, \& Shejwal, 2015).

Therefore, one of the alternatives was to create a steel support structure with an aluminum frame that was accepted because the elasticity modulus (Young) of the steel is about 3 times that of aluminum and is much more resistant to deformation. 


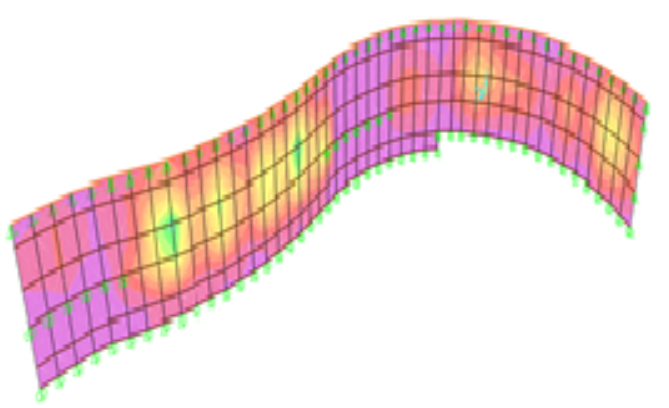

A
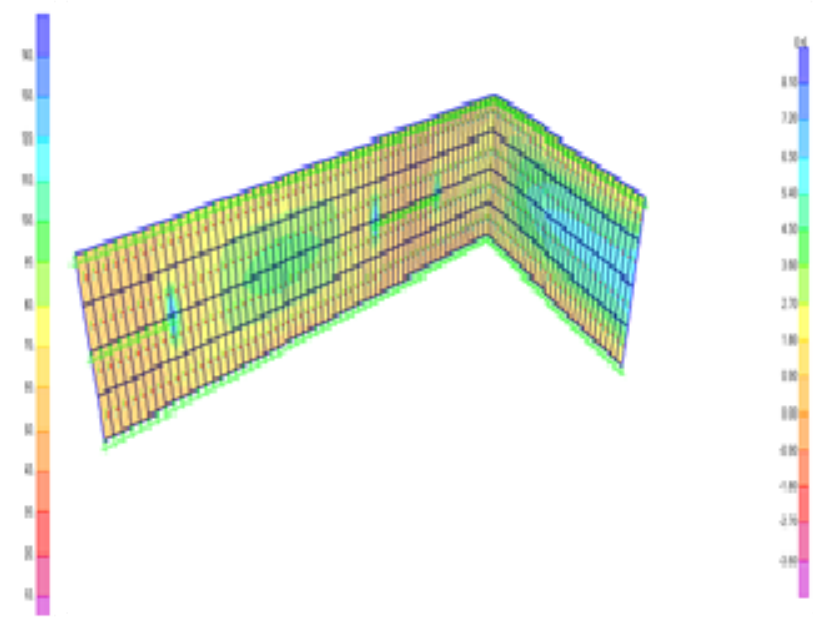

$B$

FIG. 6 Faculty of Art building Curtain wall analysis in two cases A) Curved. B) Flat

Placing a steel pillar behind each aluminium pillar can significantly increase the structural resistance to lateral forces, but there must be a separate foundation and floor for each of these pillars that will be costly and time consuming to implement. In many glass facade constructions, the facade is usually reinforced with a twodimensional or three-dimensional truss from behind or in front, but while occupying the interior area, its twodimensional type requires off-screen elements that lead to three-dimensional and practically limiting the view of the inside of the building to the outside, reducing its performance while still having significant costs.

Placing a limited number of large steel pillars and rolled metal beams as a midrange support can be a good idea. As the number of pillars is limited, it also reduces the cost of running the foundation. Using this idea, an adjoin structure is added to the appropriate model and the re-model is analysed based on finite element theory. Figure 6 illustrates the results of the analysis and displacement of two different flat and curved structures. It should be noted that the steel circular beam was positioned slightly above the mid-height of the glass wall to prevent sighting and to move parallel to the aluminium frames and to increase the wind force at altitude.

\subsection{Central Organization Building of Bojnourd University}

In order to achieve the appropriate model, all kinds of aluminum profiles available in the market for this system were introduced for analysis and were optimized in several stages of analysis and design of the lightest sections that could do a load-bearing placed on the structure. In both curved and flat models, 514 linear elements and 512 surface elements were used and final results were obtained using several steps of analysis and design. In the initial analysis, it was found that the displacement of the flat structure between floors was more than twice that of the curved structure and also it required stronger profiles to control stress. The most important result is that in the curved model, due to the larger area (a longer length of the elements) due to the curved shape, the lighter structure is able to bear the load and resist them. Therefore, in this case study, despite having about $3 \%$ more floor area, the weight of the curtain wall was reduced by about $20 \%$ due to its curved shape against wind force (Table 1).

TABLE 1 Comparison of the facades area and the minimum weight required of their structures

\begin{tabular}{llll}
\hline Row & Type & Area (square mete) & Weight of aluminum frame (Kg) \\
1 & Flat model & 269 & 676 \\
\hline 2 & Curved model & 278 & 531 \\
\hline
\end{tabular}

\subsection{Faculty of Art Building}

The modeling of the aluminum profiles used for this system was introduced in the software and the analysis and design were carried out to achieve a multi-stage optimal design. The lightest sections that could do load-bearing on this structure were identified. Both curved and flat models use 519 linear elements and 370 surface elements. The most noteworthy result is that in the curved model, despite the larger surface area and thus the longer length of the elements due to the curved shape, the lighter structure is able to bear the load and resist them. Therefore, in this case study, despite having about $7 \%$ more floor area, the weight of the curtain wall was reduced by about $30 \%$ due to its curved shape against wind force (Table 2). 
TABLE 2 Comparison of the facades area and the minimum weight required of their structures

\begin{tabular}{llclll}
\hline Row & Type & $\begin{array}{c}\text { Area } \\
\left(\mathbf{m}^{\mathbf{2}}\right)\end{array}$ & $\begin{array}{l}\text { Weight of aluminum } \\
\text { frame } \mathbf{( K g )}\end{array}$ & $\begin{array}{l}\text { Weight of steel support } \\
\text { structure } \mathbf{( K g )}\end{array}$ & $\begin{array}{l}\text { Total weight } \\
(\mathbf{K g})\end{array}$ \\
\hline 1 & Flat model & 466 & 2363 & 1769 & 4132 \\
\hline 2 & Curved model & 501 & 1275 & 1526 & 2801 \\
\hline
\end{tabular}

\section{Conclusion}

Free-form architecture is one of the major challenges for architects, engineers, and the building industry (Castaneda, Lauret, Lirola, \& Ovando, 2015). The findings show that curved shapes such as domes and barrel vaults are optimally supported by vertical geometrical loads on the walls of the Curtin Wall because essentially the lateral load of the wind is determining as the main force in designing these structures. Thus, the curved designs in the plan, even though they increase the area and the length of the elements (which in architectural term can create more space), are more optimally structured and they have lower weight and expenses. On the other hand, because these elements are created in the curved path of flat modules (flat glass) that are angled according to the design, the implementation of the curve shape due to breaking into small polygon modules is not more costly than the flat form. Therefore, it is concluded that in the design of Curtain Wall facades the curved form is better than the flat. Therefore, the curved form was finally selected and executed for the glass facade of the buildings of the Central Organization of the Bojnourd University and The Faculty of Art (Figure 7)

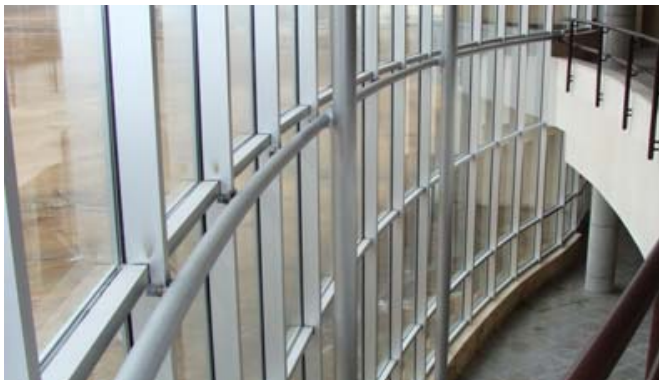

A

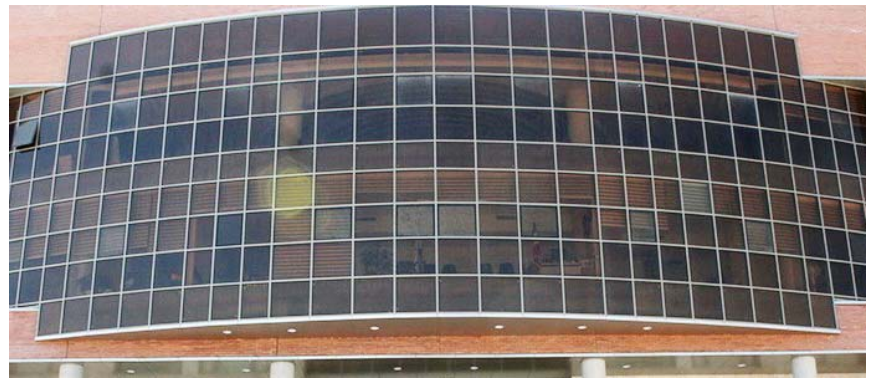

$B$

FIG.7 Curtain wall implemented, A) Faculty of Art B) Central Organization

Although the curtain walls are more discussed in architectural terms, they relate to their behavior to the structure beyond normal walls or windows and must be analyzed and designed by structural engineers in three dimensions. It is therefore required for modeling, glass facades and is significantly different from manual analysis for the following reasons:

1. Curved walls have particular 3D behavior.

2. The effect of the presence or absence of discontinuity on the walls of the Curtain wall is determined in $3 \mathrm{D}$ analysis.

3. The combination of elements of different materials (such as iron and aluminum) is well applied in software models and, if necessary, combining the materials (e.g. aluminum for lightness and beauty and iron for greater strength) can create an effective system.

4. The wind force has significantly determined these walls, which is better investigated in the 3D model under different conditions.

5. In a 3D model with a graphical representation, we can have a better understanding of the physical reality of the wall and can easily analyze and design after applying changes or considering different solutions.

6. By modeling the glass in the $3 \mathrm{D}$ model while taking into account its hardness in structural analysis, it is possible to apply the wind load to a surface that is more precise, and even control the glass's deflection and breaking probability.

7. Due to the capability of finite element software in understanding the aluminium sections and design codes of aluminum structures (in addition to steel), it is a good capability to model these types of walls.

8. Finite element analysis of walls is only possible with a computer and can provide reliable results if the structures and inputs are properly defined. 


\section{References}

[1] Richman, R.C., \& Pressnail, K.D. (2009). A more sustainable curtain wall system: Analytical modeling of the solar dynamic buffer zone (SDBZ) curtain wall. Building and Environment, Vol. 44, 1-10

[2] Baniotopoulos, C., Nikolaidis, T., \& Moutsanidis, G. (2016). Optimal structural design of glass curtain-wall systems. Structures and Buildings, Vol 169, No. 6, 450-457

[3] Brzezicki, M., (2018). Classification of Oblique Grids in Curtain Walls: A Case Study of Design Strategies in Modular Edge-Panels. Journal of Facade Design and Engineering, Vol. 6, No 1, 101-115

[4] Bedon, C., \& Amadio, C., (2018). Numerical assessment of vibration control systems for multi-hazard design and mitigation of glass curtain walls. Journal of Building Engineering, Vol. 15, 1-13

[5] Yi, Y. K., Sharston, R., \& Barakat, D. (2019). Auxetic Structures and Advanced Daylight Control Systems. Journal of Facade Design and Engineering, Vol. 7, 63

[6] Rapone, G., \& Saro, O. (2012). Optimization of curtain wall facades for office buildings by means of PSO algorithm. Energy and Buildings, Vol. 45, 189-196

[7] Kazmierczak, K., (2010). REVIEW OF CURTAIN WALLS, FOCUSING ON DESIGN PROBLEMS AND SOLUTIONS. Design and Rehabilitation - Session EE4-1

[8] Juaristi, M., Barrio, A. M., Knaack, U., \& Acebo, T.G. (2018). Smart and Multifunctional Materials and their Possible Application in Façade Systems. Journal of Facade Design and Engineering, Vol. 6. N. 3

[9] Kassem, M., \& Mitchell, D. (2015). Bridging the gap between selection decisions of facade systems at the early design phase: Issues, challenges and solutions. Journal of Facade Design and Engineering, Vol. 3, 165-183

[10] Ilter, E., Tavil, A., \& Celik, O. C. (2015). Full scale performance testing and evaluation of unitized curtain walls. Journal of Facade Design and Engineering, Vol. 3, 39-47

[11] Taywade, P., \& Shejwal, S. (2015). Structural Design of a Glass Façade. International Journal of Scientific and Research Publications, Vol. 5, 3

[12] Castaneda, E., Lauret, B., Lirola, J.M., \& Ovando, G. (2015). Free-form architectural envelopes: Digital processes opportunities of industrial production at a reasonable price. Journal of Facade Design and Engineering Vol. 3, 1-13 